\title{
INFLUÊNCIA DA ANTIBIOSE EXERCIDA POR ACTINOMICETOS ÀS ESTIRPES DE BRADYRHIZOBIUM SPP., NA NODULAÇÃO DA SOJA ${ }^{1}$
}

\author{
JOÃO CARLOS PEREIRA, MARIA CRISTINA PRATA NEVES² e ADAM DROZDOWICZ ${ }^{3}$
}

\begin{abstract}
RESUMO - Este trabalho teve por objetivo avaliar o espectro antibiótico de actinomicetos provenientes de solos de Cerrados e a sua influência na nodulação da soja. As estirpes BR 29, BR 33, BR 40, BR 85, BR 86, BR 96, 47/587, 3B-7 e 4A-5 de Bradyrhizobium spp. apresentaram comportamento diferenciado em relação à resistência natural aos antibióticos produzidos por 204 actinomicetos. As estirpes BR 29 e BR 96 foram sensíveis a 5,2 e 9,9\% dos antibióticos produzidos, respectivamente, enquanto a BR 33 apresentou sensibilidade a 20,3\%. O antagonismo exercido pelos actinomicetos exclusivamente à BR 29 e BR 33 foi de 1,6 e 5,7\%, respectivamente. Esse efeito não foi observado nas estirpes BR 40 e BR 96. Inoculações simples e em mistura das estirpes na presença de actinomicetos influenciaram a nodulação da soja. A co-inoculação da BR 33 e BR 29 com o isolado 370 reduziu o percentual de ocorrência média, nos nódulos, da BR 29 , de $94,1 \%$ para $83,7 \%$, com conseqüente aumento da BR 33 de $6,7 \%$ para $17,2 \%$. Os resultados evidenciam a importância de estudos ecológicos desses microrganismos, visando avaliar o seu papel no estabelecimento de uma nodulação eficiente.

Termos para indexação: cerrados, fixação simbiótica do $\mathrm{N}_{2}$, capacidade competitiva, antagonismo.
\end{abstract}

\section{INFLUENCE OF ANTIBIOSIS PRODUCED BY ACTINOMYCETES ON STRAINS OF BRADYRHIZOBIUM SPP. ON SOYBEAN NODULATION}

\begin{abstract}
The aim of this work was to evaluate the antibiotic spectrum of actinomycetes from Cerrado soils and their influence on soybean nodulation. Strains BR 29, BR 33, BR 40, BR 85, BR 86, BR 96, 47/587, 3B-7 and 4A-5 of Bradyrhizobium spp. were characterized by their natural resistence to antibiotics produced by 204 actinomycete isolates. The strains BR 29 and BR 96 of B. elkanii were sensitive to $5.2 \%$ and $9.9 \%$ the products of actinomycete isolates, respectively, while BR 33 was sensitive up to $20.3 \%$. The antagonistic effects caused by actinomycete exclusively to BR 29 and BR 33 were $1.6 \%$ and 5.7\% respectively. This effect was not observed for strains BR 40 and BR 96 . Single and multistrains inoculations in the presence or absence of actinomycetes affected soybean nodulation. On double strain inoculations, with BR 33 and BR 29 mixed with actinomycete 370 there was a decrease in nodule occupancy by BR 29 from $94.1 \%$ to $83.7 \%$ with concomitant increase in the occupying of BR 33 from $6.7 \%$ to $17.2 \%$. The results indicate the importance of ecological studies on actinomycetes population in order to access their role in the establishment of efficient nodulation
\end{abstract}

Index terms: cerrado, $\mathrm{N}_{2}$ symbiotic fixation, competition capacity, antagonism.

${ }^{1}$ Aceito para publicação em 2 de junho de 1998. Extraído da dissertação de Doutorado do primeiro autor apresentada à UFRRJ.

${ }^{2}$ Eng. Agr., Ph.D., Embrapa-Centro Nacional de Pesquisa de Agrobiologia (CNPAB), Estrada Rio - São Paulo, Km 47, Caixa Postal 74505, CEP 23851-970 Seropédica, RJ. E-mail: jpereira@cnps.embrapa.br

${ }^{3}$ Biólogo, Ph.D., Instituto de Microbiologia, Universidade Federal do Rio de Janeiro (UFRJ), Centro de Ciência da Saúde, Bloco F, Ilha do Fundão, CEP 21941-590 Rio de Janeiro, RJ.

\section{INTRODUÇÃO}

Em solos de Cerrados a principal fonte de N para a cultura da soja (Glycine max (L.) Merrill) é a fixação simbiótica do $\mathrm{N}_{2}$, com bactérias diazotróficas denominadas Bradyrhizobium spp. Desta forma, têm-se obtido até $4.000 \mathrm{~kg}$ de grãos/ha sem a utilização de fertilizantes nitrogenados (Peres et al., 1982).

Por outro lado, tem-se verificado que a introdução desta leguminosa nesses solos pode apresentar 
problemas relacionados com a nodulação (Oliveira et al., 1991). Diferenças na eficiência das estirpes de Bradyrhizobium que nodulam a soja têm sido observadas (Döbereiner et al., 1970; Duque et al., 1982), podendo ter, como conseqüências, respostas diferenciadas da inoculação em relação ao crescimento da planta e à produtividade da cultura (Vargas et al., 1994).

Em solos de Cerrados com histórico de cultivo de soja, tem-se observado que a inoculação da estirpe BR 33, com maior eficiência nodular (Neves et al., 1985), nem sempre tem incrementado a fixação simbiótica do $\mathrm{N}$, visto que nesses solos a ocorrência das estirpes BR 29 e BR 96 nos nódulos da soja tem sido predominante, chegando a formar $90 \%$ dos nódulos nessa leguminosa (Peres, 1979; Vargas et al., 1982a, 1982b, 1994; Vargas \& Suhet, 1980). Também tem-se observado um incremento da ocorrência da estirpe BR 40, de menor eficiência simbiótica, nos nódulos da soja. Em 1970, esta estirpe ocupou 2\% dos nódulos quando usada como inoculante nos Cerrados. A adaptação às condições dos Cerrados resultou em incrementos da sua capacidade competitiva. Atualmente, estirpes pertencentes ao sorogrupo BR 40 são encontradas em aproximadamente 60\% dos nódulos, interferindo no estabelecimento, nos nódulos, de outras estirpes, inoculadas através das sementes (Vargas et al., 1994).

Diversos fatores abióticos e bióticos podem modificar os padrões competitivos das estirpes de Bradyrhizobium spp. Entre os fatores bióticos, as populações de actinomicetos na comunidade bacteriana dos solos tropicais têm recebido atenção especial, pelo seu potencial na produção de antibióticos, visto que $85 \%$ dos antibióticos conhecidos são produzidos por esses microrganismos (Gottlieb, 1973). Em solos de Cerrados com vegetação nativa, a ocorrência das populações de actinomicetos na comunidade microbiana pode ser superior a $75 \%$, com predominância do gênero Streptomyces (Coelho \& Drozdowicz, 1978). Perturbações no solo de um ecossistema natural através de práticas agrícolas, como a calagem, têm resultado em desequilíbrios das populações na comunidade microbiana, favorecendo as populações de actinomicetos (Baldani et al., 1982; Kamel et al., 1989; Cattelan \& Vidor, 1990; Pereira et al., 1996) e alterando os percentuais de ocor- rência das estirpes de rizóbio resistentes a antibióticos (Vargas et al., 1992a).

Problemas relacionados com a nodulação da soja, nos primeiros anos de cultivo de Cerrado, têm sido atribuídos à predominância das populações de actinomicetos com ação antagônica, através da produção de antibióticos, sobre as populações de rizóbio (Scotti et al., 1988). O elevado percentual de ocorrência das estirpes BR 29 e BR 96 nos nódulos da soja tem sido atribuído à resistência a antibióticos, já que foi observado que elas apresentam resistências naturais elevadas à estreptomicina, cloranfenicol e tetraciclina (Scotti et al., 1982, 1988).

Assim, na cultura da soja, além da eficiência fixadora, deve-se considerar os fatores que influenciam a capacidade competitiva das estirpes de B. elkanii e B. japonicum, para que o potencial de fixação biológica do $\mathrm{N}_{2}$ seja maximizado. Nessa situação, as estirpes presentes nos inoculantes comerciais necessitam competir ativamente por substratos e pelos microssítios já ocupados pelos demais microrganismos.

O presente trabalho teve por objetivo avaliar o espectro antibiótico de isolados de actinomicetos provenientes de solos de Cerrados e a sua influência na capacidade competitiva por sítios de nódulos formados na soja por estirpes de Bradyrhizobium spp.

\section{MATERIAL E MÉTODOS}

A resistência natural de estirpes de Bradyrhizobium spp. ao antagonismo promovido por actinomicetos foi avaliada utilizando-se as estirpes de Bradyrhizobium japonicum: BR 33 [CB 1809], BR 85 [CPAC-7, originária de uma cultura da estirpe BR 33, com elevada eficiência fixadora], e 47/587 [BR 33 readaptada em solos de cerrado] e as estirpes de Bradyrhizobium elkanii: BR 40 [SEMIA 566], BR 86 [CPAC-15, diferindo da BR 40 pela eficiência fixadora e pela elevada capacidade competitiva], 3B-7 e 4A-5 [isoladas a partir da BR 40 com capacidade competitiva semelhante e elevada em relação a original, respectivamente] (Scotti, 1993; Vargas et al., 1994), BR 29 [29W] e BR 96 [SEMIA 587] utilizadas nos inoculantes comerciais, todas pertencentes à coleção de culturas da Embrapa-CNPAB.

A seleção dos actinomicetos isolados de solos de Cerrados, em diferentes condições ambientais, foi feita com base nas diferenças morfológicas que as colônias apresentaram em placas-de-Petri, contendo meio de cultura des- 
crito por Waksman (1961). Os isolados de actinomicetos foram preservados na forma de esporos, em glicerol esterilizado a $10 \%$ ( $\mathrm{vol} / \mathrm{vol}$ ) e mantidos a $-20^{\circ} \mathrm{C}$ (Wellington $\&$ Williams, 1978).

A atividade antagônica dos isolados de actinomicetos foi avaliada em placas-de-Petri com meio Waksman utilizando-se as estirpes descritas anteriormente. Em cada placa, foi inoculada uma gota de suspensão de esporos de seis isolados de actinomicetos. Após 48 horas de incubação (quando as colônias estavam visíveis), as placas foram invertidas, para adição, na tampa, de $1 \mathrm{~mL}$ de clorofórmio, e incubadas por quarenta minutos. Para eliminação dos vapores de clorofórmio, as placas foram deixadas semi-abertas na capela, com fluxo laminar de ar por vinte minutos. Em seguida, as colônias de actinomicetos foram cobertas com $10 \mathrm{~mL}$ do meio Vincent (1970) liquefeito com temperatura em torno de $40^{\circ} \mathrm{C}$, ao qual se adicionou previamente uma suspensão de cada estirpe de Bradyrhizobium com aproximadamente $10^{8}$ células $/ \mathrm{mL}$ de meio.

Para avaliar a influência dos isolados de actinomicetos na nodulação da soja por estirpes de Bradyrhizobium spp., foi instalado um experimento em casa de vegetação, com vasos Leonard contendo vermiculita e areia na proporção de $2: 1$, esterilizados em autoclave por duas horas, a $121^{\circ} \mathrm{C}$ e 1,5 atm. Os isolados de actinomicetos $\mathrm{n}^{\circ} 37$ (antagônico à estirpe BR 33 em meio de cultura), $n^{\circ} 42$ (antagônico à estirpe 47/587), $n^{\circ} 85$ (antagônico à BR 96), n ${ }^{\circ} 370, n^{\circ} 372$ (antagônicos à BR 29) e no 368 (antagônico à BR 29, BR 33, 47/587 e BR 96) foram utilizados como inóculos. Para isto, foram repicados individualmente em meio Waksman líquido, e incubados por sete dias em temperatura ambiente com agitação horizontal constante. Nos tratamentos com actinomicetos, adicionaram-se, superficialmente, em cada vaso, $3 \mathrm{~mL}$ da suspensão contendo o isolado específico e mais $25 \mathrm{~mL}$ do meio Waksman líquido. As inoculações dos isolados de actinomicetos foram feitas nove dias antes da semeadura e da inoculação das estirpes de Bradyrhizobium spp., considerando-se a menor taxa de crescimento que as populações de actinomicetos normalmente apresentam.

As estirpes BR 29, BR 33, BR 96 e 47/587, utilizadas como inóculos, foram repicadas individualmente em meio Vincent líquido, e incubadas, por sete dias, a $28^{\circ} \mathrm{C}$, com agitação horizontal de $150 \mathrm{rpm}$. Em seguida, as suspensões bacterianas foram equalizadas por turbidimetria em relação à menos turva, para padronização do número de células por mililitro de suspensão. O número de células de cada suspensão foi determinado pelo método de diluições em placas, obtendo-se concentrações em torno de $10^{8}$ células $/ \mathrm{mL}$. As estirpes foram inoculadas na semeadura, à razão de $2 \mathrm{~mL} /$ semente.
Semearam-se seis sementes por vaso da cultivar de soja Doko, previamente desinfestadas em álcool, $96^{\circ} \mathrm{GL}$ por cinco minutos, $\mathrm{HgCl}_{2} 0,1 \%$ por dois minutos e sete lavagens consecutivas com água destilada esterilizada. Nove dias após, foi feito o desbaste, deixando-se duas plantas por vaso.

O delineamento experimental utilizado foi de blocos completos casualizados, com quatro repetições, e os seguintes tratamentos: BR 33, 47/587, BR 29, BR 96, BR 33 + isolado de actinomiceto 37 (antagônico à BR 33), $47 / 587$ + isolado 42 (antagônico à 47/587), BR 29 + isolado 370 (antagônico à BR 29), BR 29 + isolado 372 (antagônico à BR 29), BR 96 + isolado 85 (antagônico à BR 96), BR 33 + BR 29, BR 33 + BR $29+$ isolado 370, BR $33+$ BR $29+$ isolado 372, BR $33+$ BR $29+$ isolado 37, BR 33 + BR 96, BR 33 + BR 96 + isolado 85, BR $33+$ BR $96+$ isolado 37, 47/587 + BR 29, 47/587 + BR $29+$ isolado $370,47 / 587+$ BR $29+$ isolado 372 , $47 / 587+$ BR $29+$ isolado 42, 47/587 + BR 96, 47/587 + BR 96 + isolado 85, 47/587 + BR 96 + isolado 42, BR $33+47 / 587+$ BR $29+$ BR 96, BR $33+47 / 587+$ BR 29 + BR 96 + isolado 368 (antagônico a todas).

A colheita foi feita quando as plantas estavam em floração plena (45 dias após semeadura), para avaliações do número e peso de nódulos secos, bem como do percentual de ocorrência das estirpes nos nódulos.

A identificação das estirpes nos nódulos foi feita por meio de reações de aglutinação entre anti-soros específicos aos diferentes sorogrupos e antígenos nodulares (Somasegaran \& Hoben, 1985). Os antígenos nodulares foram preparados por maceramento individual de 30 nódulos por vaso em solução fisiológica $(\mathrm{NaCl} 0,85 \%)$, em volume variável conforme o tamanho do nódulo. Do sobrenadante, adicionou-se horizontalmente uma gota de $15 \mu \mathrm{L}$ em placas de vidro. No sentido vertical, adicionou-se o mesmo volume dos anti-soros das estirpes BR 33 e BR 29 ou BR 96, diluídos 25 vezes, e uma gota de solução fisiológica, para observação de possíveis reações espontâneas. Consideraram-se como positivas, as suspensões claras com aglutinações; e negativas, as suspensões turvas com ausência de aglutinação.

\section{RESULTADOS E DISCUSSÃO}

\section{Resistências de estirpes de Bradyrhizobium spp. aos antibióticos produzidos por actinomicetos}

As resistências naturais das estirpes aos antibióticos produzidos pelos actinomicetos, oriundos dos solos de Cerrados, foram diferenciadas (Tabela 1). As estirpes BR 29, BR 96 e BR 40 mostraram-se sen- 
síveis aos antibióticos produzidos, respectivamente, por 5,$2 ; 9,9$ e $9,9 \%$ dos 204 isolados de actinomicetos testados, enquanto a estirpe BR 33 apresentou sensibilidade a $20,3 \%$ desses isolados.

Tal variabilidade também foi observada quanto às estirpes de um mesmo sorogrupo. As sensibilidades das estirpes BR 85 e 47/587 foram semelhantes, mas inferiores à da estirpe-matriz BR 33. No sorogrupo BR 40, a estirpe BR 86 foi sensível aos antibióticos produzidos por $7,8 \%$ dos actinomicetos, ao passo que o crescimento das estirpes $3 \mathrm{~B}-7$ e $4 \mathrm{~A}-5$ foi inibido, respectivamente, por 14,6 e $13,0 \%$ dos isolados de actinomicetos testados. Nessas condições, a adaptação das estirpes 3B-7 e 4A-5, em solos de Cerrados, não resultou em aumentos das resistências aos antibióticos produzidos pelos actinomicetos oriundos desses solos; ao contrário, apresentaram maior sensibilidade em relação à estirpe original.

Verificou-se, ainda, que 7,3\% dos isolados de actinomicetos apresentaram antagonismo simultâneo às estirpes BR 33, BR 85 e 47/587 (pertencentes ao sorogrupo BR 33), enquanto, 1,6\% dos isolados foram antagônicos às estirpes $\mathrm{BR} 40, \mathrm{BR} 86,3 \mathrm{~B}-7 \mathrm{e}$ 4A-5 (sorogrupo BR 40). Por outro lado, o antagonismo a todos os sorogrupos não foi observado. Esses resultados poderiam explicar por que a inoculação da estirpe BR 33 em solos com histórico

TABELA 1. Sensibilidade natural das estirpes de Bradyrhizobium spp. aos antibióticos produzidos por isolados de actinomicetos, oriundos de solos de Cerrados.

\begin{tabular}{lcc}
\hline \multirow{2}{*}{ Estirpes } & \multicolumn{2}{c}{ Actinomicetos } \\
\cline { 2 - 3 } & Antagônicos & $\begin{array}{c}\text { Antagônicos } \\
\text { específicos }\end{array}$ \\
\hline & $-1-1,-1,6$ \\
BR 29 & 5,2 & 4,2 \\
BR 96 & 9,9 & 5,7 \\
& & 3,6 \\
BR 33 & 20,3 & 1,0 \\
BR 85 & 16,1 & \\
47 / 587 & 16,7 & 0,0 \\
& & 0,0 \\
BR 40 & 9,9 & 4,2 \\
BR 86 & 7,8 & 1,0 \\
3B-7 & 14,6 & \\
4A-5 & 13,0 & \\
\hline
\end{tabular}

de cultivo de soja nem sempre tem incrementado a fixação simbiótica do $\mathrm{N}$, já que tem-se observado a predominância de estirpes pertencentes a outros sorogrupos.

$\mathrm{O}$ antagonismo exercido pelos actinomicetos especificamente a cada estirpe também foi variável. Verifica-se que $1,6 \%$ dos isolados apresentaram antagonismo exclusivamente à estirpe BR 29, e 5,7\% à estirpe BR 33. Esse efeito não é observado quanto às estirpes BR 40 e BR 86. Isso evidencia que nestes solos o amensalismo exercido pelos actinomicetos por meio da produção de antibióticos pode ser específico tanto no que diz respeito às estirpes de Bradyrhizobium elkanii como no tocante às estirpes de Bradyrhizobium japonicum.

Por outro lado, observou-se que nenhum isolado de actinomicetos foi antagônico a todas as estirpes testadas. Resultado semelhante foi obtido por Patel (1974), que testou 279 actinomicetos, e nenhum foi antagônico a todas as 12 estirpes de Rhizobium utilizadas.

Assim, a alta capacidade das estirpes BR 29 e BR 96 de sobreviver e colonizar os solos de Cerrados e de competir por sítios de nódulos formados na soja cultivada nestes solos (Vargas et al., 1992a, 1993; Scotti, 1993) pode estar associada com suas baixas sensibilidades aos antibióticos produzidos pelas populações de actinomicetos desses solos.

A variabilidade apresentada pelas estirpes B. elkanii e B. japonicum, em relação à sensibilidade aos antibióticos produzidos pelos actinomicetos, pode estar relacionada com a antibiose exercida pelas populações pertencentes à comunidade microbiana dos solos dos quais elas foram isoladas. Assim, o percentual de microrganismos antagônicos presentes no solo seria um fator determinante do nível de sensibilidade apresentado pelas estirpes aos antibióticos produzidos pelos actinomicetos. Além disso, deve-se considerar que a acidez do solo (Ramos et al., 1987; Vargas et al., 1993), assim como a inativação, a estabilidade química e a degradação microbiana dos antibióticos também poderiam influenciar os padrões de sensibilidade natural das estirpes de rizóbio aos antibióticos produzidos (Williams, 1982; Williams \& Vickers, 1986; Scotti et al., 1988).

Os dados acima relacionados sugerem que o tamanho e a composição das populações de B. elkanii 
e B. japonicum nos solos de Cerrados podem ser influenciados pelas interações com as populações de actinomicetos, mediante a produção de antibióticos. Entretanto, deve-se considerar que a presença da planta hospedeira seria outro fator determinante das características quantitativa e qualitativa das populações de Bradyrhizobium spp. nos solos, já que existem fortes evidências de que os antibióticos são produzidos na rizosfera, o que poderia inibir a infecção e a formação de nódulos pelas estirpes de rizóbio sensíveis a esses antibióticos (Ramos et al., 1987).

\section{Influência da inoculação de isolados de actinomicetos sobre a nodulação da soja por estirpes de Bradyrhizobium spp.}

As inoculações simples e mistas das estirpes de Bradyrhizobium spp., na ausência e presença de isolados de actinomicetos antagônicos, influenciaram significativamente o peso de nódulos secos, porém as diferenças observadas em números de nódulos não foram significativas (Tabela 2). Os pesos de nódulos secos variaram de $116,2 \mathrm{mg} /$ planta, quando as plantas foram infectadas com a mistura das estirpes BR 33 e BR 29 na presença do isolado de actinomiceto 372, a $252 \mathrm{mg} /$ planta, quando a estirpe BR 33 foi inoculada na presença do isolado 37. Tais valores são superiores aos reportados por Oliveira (1982), que observou pesos médios de nódulos secos variando de 45 a $163 \mathrm{mg}$ por vaso. Em condições de campo, Vargas et al. (1993) consideraram, para uma nodulação adequada de soja no início da floração, a produção de 100 a $200 \mathrm{mg}$ de nódulos secos por planta.

$\mathrm{Na}$ ausência dos isolados de actinomicetos, o número e o peso de nódulos secos das plantas infectadas com as estirpes BR 33, 47/ 587, BR 29 e BR 96 não diferiram significativamente. Entretanto, a inoculação, na soja, da estirpe BR 33 em solo de Cerrado no primeiro ano de cultivo, tem resultado em números de nódulos menores em comparação com outras estirpes, podendo ser onze vezes inferior quando se utiliza a mistura das estirpes BR 29 e BR 96 (Oliveira et al., 1991).

As plantas infectadas com a BR 33 na presença do isolado antagônico 37 (antagonista a esta estirpe em placas-de-Petri) apresentaram tendência para formar menor número de nódulos em relação aos
38,7 nódulos/ planta formados com a inoculação desta estirpe na ausência de isolados de actinomicetos. Entretanto, a presença deste isolado aumentou o peso de nódulos secos, sendo que este efeito não é observado nas inoculações mistas dessa estirpe com outras. Em relação às demais estirpes, não se observam diferenças significativas na nodulação quando as estirpes foram inoculadas com os respectivos antagonistas.

TABELA 2. Número e peso de nódulos secos na cultivar de soja Doko, em vasos Leonard, em resposta à inoculação com isolados de actinomicetos. Médias de quatro repetições ${ }^{1}$.

\begin{tabular}{|c|c|c|}
\hline \multirow[t]{2}{*}{ Tratamento } & \multicolumn{2}{|c|}{ Nodulação } \\
\hline & $\mathrm{N} \%$ planta & $\mathrm{mg} /$ planta \\
\hline BR 33 & 38,7 & $160,6 \mathrm{bcdef}$ \\
\hline $47 / 587$ & 34,6 & 199,6 abcdef \\
\hline BR 29 & 45,2 & $189,2 \mathrm{abcdef}$ \\
\hline BR 96 & 46,3 & 200,2abcdef \\
\hline BR $33+$ isolado de actinomiceto $37^{2}$ & 33,5 & $252,0 \mathrm{a}$ \\
\hline $47 / 587+$ isolado 42 & 33,1 & $173,2 \mathrm{abcdef}$ \\
\hline BR $29+$ isolado 370 & 52,0 & $217,1 \mathrm{abcd}$ \\
\hline BR $29+$ isolado 372 & 54,7 & 188,6 abcdef \\
\hline BR $96+$ isolado 85 & 44,6 & $221,6 \mathrm{abcd}$ \\
\hline BR $33+$ BR 29 & 46,5 & $243,3 \mathrm{ab}$ \\
\hline BR $33+$ BR $29+$ isolado 370 & 29,5 & $127,5 \mathrm{ef}$ \\
\hline BR $33+$ BR $29+$ isolado 372 & 44,2 & $116,2 \mathrm{f}$ \\
\hline BR $33+$ BR $29+$ isolado 37 & 38,7 & 204,1 abcde \\
\hline BR 33 + BR 96 & 33,1 & 197,0abcdef \\
\hline BR $33+$ BR $96+$ isolado 85 & 43,1 & 210,0abcde \\
\hline BR $33+$ BR $96+$ isolado 37 & 46,6 & $225,7 \mathrm{abc}$ \\
\hline $47 / 587+$ BR 29 & 42,5 & 205,1abcde \\
\hline $47 / 587+$ BR $29+$ isolado 370 & 45,6 & 194,8abcdef \\
\hline $47 / 587+$ BR $29+$ isolado 372 & 30,5 & $135,0 \mathrm{df}$ \\
\hline $47 / 587+$ BR $29+$ isolado 42 & 44,8 & 207,2abcde \\
\hline 47/587 + BR 96 & 41,8 & $220,3 \mathrm{abcd}$ \\
\hline $47 / 587+$ BR $96+$ isolado 85 & 41,3 & 191,1abcdef \\
\hline $47 / 587+$ BR $96+$ isolado 42 & 30,0 & $166,5 \mathrm{abcdef}$ \\
\hline BR 33 + 47/587 + BR 29 + BR 96 & 40,2 & $155,0 \mathrm{cef}$ \\
\hline $\begin{array}{l}\text { BR } 33+47 / 587+\text { BR } 29+B R 96+ \\
\text { isolado } 368\end{array}$ & 41,0 & 194,7abcdef \\
\hline
\end{tabular}


A inoculação simultânea da BR 29 e BR 33, na presença dos isolados 370 e 372 (antagônicos à BR 29), resultou, respectivamente, em decréscimos de 36,6 e 4,9\% no número de nódulos formados em relação à ausência desses isolados, com reduções significativas no peso de nódulos formados. O menor peso de nódulos apresentados pelas plantas na presença desses isolados poderia estar associado com mudanças nos percentuais de ocupação dos nódulos pelas estirpes BR 33 e BR 29, visto que, entre estas, a BR 33 apresenta como característica a produção de menor peso de nódulos secos (Oliveira, 1982; Oliveira et al., 1991). Por outro lado, a inoculação mista das estirpes 47/587 e BR 29, na presença dos isolados 370 e 372 , resultou em variações não-significativas do peso de nódulos secos. Além disso, as demais inoculações mistas na presença de isolados de actinomicetos antagonistas não resultaram em variações significativas no número e peso de nódulos secos.

Influência da inoculação de isolados de actinomicetos na capacidade competitiva por sítios de nódulos de soja, induzidos por estirpes de Bradyrhizobium spp.

A tipificação sorológica dos nódulos permitiu avaliar a influência dos isolados de actinomicetos na capacidade das estirpes de Bradyrhizobium spp. em competirem por sítios de nódulos formados na cultivar de soja Doko (Tabela 3). Para isto, utilizaram-se os anti-soros das estirpes BR 29, BR 33 e BR 96, já que a estirpe $47 / 587$ pertence ao mesmo sorogrupo da estirpe BR 33.

A tipificação sorológica dos nódulos dos vasos inoculados com as estirpes individualmente indicou que não houve contaminações entre os tratamentos, pois as suspensões nodulares reagiram somente com o anti-soro da estirpe inoculada no vaso.

Nos tratamentos sem inoculação de isolados de actinomicetos, as ocorrências médias das estirpes BR 29 e BR 96 nos nódulos de soja variaram, respectivamente, de 66,1 a $95,6 \%$ e de 22,6 a $94,8 \%$. A alta capacidade competitiva dessas estirpes também foi observada em experimentos conduzidos em solo com populações estabelecidas de Bradyrhizobium spp. e em solos de Cerrados (Vargas \& Suhet, 1980; Lira Júnior et al., 1993; Peres et al., 1993). Por outro lado, verifica-se que a indução na formação dos nódulos pelas estirpes BR 33 e 47/587, na ausência de isolados de actinomicetos, variou, respectivamente, de 6,7 a $23,5 \%$ e de 4,4 a $6,8 \%$, evidenciando que elas são menos competitivas do que as outras duas. Estes dados confirmam resultados anteriores nos quais a estirpe BR 33 apresentou baixa capacidade competitiva (Peres, 1979; Oliveira, 1982). Observa-se, também, que a adaptação da estirpe BR 33 (47/587) nos solos de Cerrados não alterou a sua capacidade competitiva.

A influência dos isolados de actinomicetos na capacidade das estirpes em competirem por sítios de nódulos formados foi variável. Verifica-se que, na inoculação mista das estirpes BR 29 e BR 33, o isolado 370, que apresentou antagonismo à BR $29 \mathrm{em}$ meio de cultura, modificou o percentual de ocorrência média dessas estirpes nos nódulos, reduzindo a presença da BR 29 de 94,1\% (tratamento sem actinomicetos) para $83,7 \%$, e, conseqüentemente, aumentando a presença da BR 33 de $6,7 \%$ para $17,2 \%$. Tal fato influenciou a nodulação, pela redução significativa do peso de nódulos secos (Tabela 2), o que pode ser atribuído à característica da estirpe BR 33 de produzir menor peso de nódulos secos (Peres, 1979; Oliveira, 1982; Oliveira et al., 1991). Na inoculação simultânea das estirpes 47/587 e BR 29, a presença desse isolado elevou os percentuais de ocupação dessas estirpes nos nódulos, além de aumentar a ocorrência de nódulos originários de infecções duplas, totalizando $2,5 \%$ dos nódulos tipificados. Esses dados sugerem que outros fatores podem estar associados com a capacidade competitiva por sítios de nódulos formados das estirpes.

A presença do isolado de actinomiceto 372 (antagônico à BR 29 em meio de cultura) não inibiu a ocupação dos nódulos pela BR 29, quando a inoculação dupla foi feita com as estirpes BR 33 e 47/587, mas influenciou a nodulação com redução significativa no peso de nódulos secos das plantas infectadas com BR 33 + BR 29 (Tabela 2). Nos tratamentos com inoculação mista das estirpes BR 33 + BR 96, e das $47 / 587$ + BR 29, as ocorrências das estirpes BR 33 e 47/587 nos nódulos da soja também não foram inibidas pelos isolados de actinomicetos que apresentaram antagonismo a estas estirpes em meio de cultura. 
A tipificação dos nódulos das plantas inoculadas com a mistura das estirpes BR $29+$ BR $96+$ BR $33+47 / 587$ evidenciou a alta capacidade competitiva da BR 29 e BR 96. Apesar de a estirpe BR 96 ter sido inoculada na concentração de $1 / 2$ em relação ao sorogrupo BR 33 (BR33 e 47/587), sua ocorrência nos nódulos chegou a $66,1 \%$. Tais dados demonstram que a ocorrência das estirpes nos nódulos pode não estar relacionada com suas concentrações no inoculante, e confirmam observações feitas por Pereira (1983), de que as estirpes mais competitivas tendem a dominar, mesmo quando utilizadas em concentrações bem menores do que outras de menor capacidade competitiva. Observa-se, também, que a presença do isolado 368, antagônico às estirpes BR 29, BR 33, BR 96 e 47/587, reduziu a ocupação da BR 29 para $61,4 \%$, e da $47 / 587$ para $2,5 \%$, ao passo que houve um incremento da BR 96, que passou a ocupar $38,6 \%$ dos nódulos tipificados. Esse isolado também proporcionou aumento da ocorrência de nódulos originários de infecções duplas.

A sorologia demonstrou, pela soma dos percentuais superiores a $100 \%$, a presença de nódulos originários de infecções duplas, resultando na ocorrência de reações de aglutinação simultâneas com diferentes graus de intensidade. As variações na intensidade das reações podem ser conseqüência das diferentes concentrações de células das estirpes nos nódulos. A ocorrência de nódulos resultantes de infecções duplas confirma observações anteriores, feitas sobre a presença de duas ou mais estirpes no mesmo nódulo (Skrdleta \& Karimova, 1969; Lindemann et al., 1974; Bromfield \& Jones, 1979; Pereira, 1983).

A capacidade competitiva por sítios de nódulos formados das estirpes de rizóbio é um caráter controlado geneticamente, variando entre estirpes (Triplett \& Sadowskky, 1992). A maior ou menor ca-

TABELA3. Ocorrência de estirpes de Bradyrhizobium spp. nos nódulos da cultivar de soja Doko em vasos Leonard, em resposta à inoculação com isolados de actinomicetos. Médias de quatro repetições.

\begin{tabular}{|c|c|c|c|}
\hline \multirow[t]{2}{*}{ Tratamento } & \multicolumn{3}{|c|}{ Sorogrupo } \\
\hline & BR 29 & BR 33 & BR 96 \\
\hline & \multicolumn{3}{|c|}{ - } \\
\hline BR $33+$ BR 29 & 94,1 & 6,7 & \\
\hline BR $33+$ BR $29+$ isolado $370^{1}$ & 83,7 & 17,2 & \\
\hline BR $33+$ BR $29+$ isolado 372 & 95,8 & 5,8 & \\
\hline BR $33+$ BR $29+$ isolado 37 & 80,7 & 20,2 & \\
\hline BR 33 + BR 96 & & 23,5 & 78,2 \\
\hline BR $33+$ BR $96+$ isolado 85 & & 14,4 & 86,4 \\
\hline BR $33+$ BR $96+$ isolado 37 & & 26,5 & 74,3 \\
\hline $47 / 587^{2}+$ BR 29 & 95,6 & 4,4 & \\
\hline $47 / 587+$ BR $29+$ isolado 370 & 97,4 & 5,1 & \\
\hline $47 / 587+$ BR $29+$ isolado 372 & 97,6 & 2,4 & \\
\hline $47 / 587+$ BR $29+$ isolado 42 & 78,4 & 22,0 & \\
\hline 47/587 + BR 96 & & 6,8 & 94,8 \\
\hline $47 / 587+$ BR $96+$ isolado 85 & & 10,2 & 89,8 \\
\hline $47 / 587+$ BR $96+i$ solado 42 & & 11,1 & 90,6 \\
\hline BR $33+47 / 587+$ BR $29+$ BR 96 & 66,1 & 11,3 & 22,6 \\
\hline$B R 33+47 / 587+B R 29+$ BR $96+$ isolado 368 & 61,4 & 2,5 & 38,6 \\
\hline
\end{tabular}

1 Estirpe e isolado de actinomiceto em itálico $\rightarrow$ antagonismo observado em placas-de-Petri.

2 Sorogrupo $47 / 587=$ BR 33 
pacidade apresentada pelas estirpes em competirem por sítios de nódulos formados também depende das boas condições fisiológicas apresentadas pela leguminosa hospedeira, e do grau de interferência dos fatores ambientais separadamente ou por meio de suas interações (Vincent, 1980).

A inoculação de estirpes mais eficientes de Bradyrhizobium pode resultar em incrementos de até $30 \%$ nos níveis de produtividade da soja (Neves et al., 1985; Vargas et al., 1992b). Por outro lado, essas estirpes são menos competitivas do que as pertencentes ao sorogrupo da estirpe BR 29 de B. elkanii. O percentual de ocorrência nos nódulos da soja das estirpes mais eficientes poderia ser incrementado com a co-inoculação com actinomicetos antagônicos específicos à estirpe BR 29. Entretanto, deve-se considerar que as interações das populações de actinomicetos com as populações de Bradyrhizobium, na rizosfera da soja, são complexas, o que sugere que muitos fatores relacionados com essas populações podem influenciar a ocorrência das estirpes nos nódulos da soja, e, conseqüentemente, a nodulação e a fixação biológica do $\mathrm{N}_{2}$. Assim, para avaliar de maneira mais adequada os efeitos desses fatores, é necessário que os estudos da ecologia desses microrganismos sejam intensificados.

\section{CONCLUSÕES}

1. As estirpes de B. elkanii e B. japonicum apresentam variações na resistência natural aos antibióticos produzidos pelos isolados de actinomicetos, oriundos de solos de Cerrados.

2. Os isolados de actinomicetos influenciam a capacidade competitiva por sítios de nódulos formados na soja, por estirpes de Bradyrhizobium spp.

3. O efeito antagônico dos isolados de actinomicetos em relação aos padrões competitivos das estirpes de Bradyrhizobium spp. influencia a nodulação da soja, por meio de variações dos pesos de nódulos secos.

\section{REFERÊNCIAS}

BALDANI, J.I.; BALDANI, V.L.D; XAVIER, D.F.; BODDEY, R.M.; DÖBEREINER, J. Efeito da calagem no número de actinomicetos e na porcentagem de bactérias resistentes à estreptomicina na rizosfera de milho, trigo e feijão. Revista de Microbiologia, São Paulo, v.13, n.3, p.250-263, 1982.

BROMFIELD, E.S.P.; JONES, D.G. The competitive ability and symbiotic effectiveness of double labelled antibiotic resistant mutants of Rhizobium trifolii. Annals of Applied Biology, Warwickshire, v.91, p.211-219, 1979

CATTELAN, A.J.; VIDOR, C. Sistemas de culturas e a população microbiana do solo. Revista Brasileira de Ciência do Solo, Campinas, v.14, p.125-132, 1990 .

COELHO, R.R.R.; DROZDOWICZ, A. The occurrence of actinomycetes in a cerrado soil in Brazil. Révue d' Ecologie et de Biologie du Sol, Paris, v.15, p.459-473, 1978.

DÖBEREINER, J.; FRANCO, A.A.; GUZMÁN, I. Estirpes de Rhizobium japonicum de excepcional eficiência. Pesquisa Agropecuária Brasileira, Série Agronomia, Rio de Janeiro, v.5, p.155-161, 1970.

DUQUE, F.F.; DIDONET, A.D.; DÖBEREINER, J. Seleção de estirpes de Rhizobium japonicum visando maior eficiência na fixação biológica do nitrogênio e na competitividade e sobrevivência no solo. In: SEMINÁRIO NACIONAL DE PESQUISA DE SOJA, 2., 1981, Brasília. Anais... Londrina: Embrapa-CNPSo, 1982. v.2, p.752-765.

GOTTLIEB, D. General consideration and implications of the actinomycetales. In: SYKES, G.; SKINNER, F.A. (Eds.). Actinomycetales: Characteristics and practical importance. London: Academic Press, 1973. p.1-10.

KAMEL, Z.; KHALIL, M.S.; SHALABY,A.M. Calcium and the biological activities of two Streptomyces species isolated, from the rizosphere of soybean plants. Journal of Basic Microbiology, Berlin, v.29, p.31-39, 1989

LINDEMANN, W.C.; SCHIMIDT, E.L.; HAM, G.E. Evidence for double infection within soybean nodules. Soil Science, Baltimore, v.118, p.274-279, 1974.

LIRA JÚNIOR, M. de A.; KOLLING, J.; PEREIRA, J.S.; BURITY, H.A.; FIGUEIREDO, M.B. do V. Competitividade de estirpes de Bradyrhizobium japonicum em fase de recomendação para a cultura 
da soja. Revista Brasileira de Ciência do Solo, Campinas, v.17, p.185-191, 1993.

NEVES, M.C.P.; DIDONET, A.D.; DUQUE, F.F.; DÖBEREINER, J. Rhizobium strain effects on nitrogen transport and distribution in soybeans. Journal of Experimental Botany, London, v.36, p.1179-1192, 1985.

OLIVEIRA, J.C.; RAMOS, M.L.G.; DUQUE, F.F. Inoculação da soja, em solo de cerrado, no primeiro ano de cultivo. Revista Brasileira de Ciência do Solo, Campinas, v.15, p.273-276, 1991

OLIVEIRA, L.A. Eficiência, capacidade competitiva e sobrevivência de estirpes de Rhizobium japonicum (Kirchner) Buchanan. Porto Alegre UFRGS, 1982. 142p. Tese de Mestrado.

PATEL, J.J. Antagonism of actinomycetes against rhizobia Plant and Soil, The Hague, v.41, p.395-402, 1974.

PEREIRA, J.C. Obtenção e avaliação de mutantes de Rhizobium phaseoli resistentes a antibióticos e fungicidas. Porto Alegre: UFRGS, 1983. 88p. Tese de Mestrado.

PEREIRA, J.C.; NEVES, M.C.P.; DROZDOWICZ, A. Quantificações das populações de bactérias em geral, de bactérias resistentes a antibióticos e de actinomicetos em solos. Seropédica: Embrapa-CNPAB, 1996. 20p. (Embrapa-CNPAB. Documentos, 26).

PERES, J.R.R. Seleção de estirpes de Rhizobium japonicum e competitividade por sítios de infecção nodular em cultivares de soja (Glycine max (L.) Merril). Porto Alegre: UFRGS, 1979. 81p. Tese de Mestrado.

PERES, J.R.R.; MENDES, I. de C.; SUHET, A.R.; VARGAS, M.A.T. Eficiência e competitividade de estirpes de rizóbio para soja em solos de cerrado. Revista Brasileira de Ciência do Solo, Campinas, v.17, p.357-363, 1993

PERES, J.R.R.; VARGAS, M.A.T.; SUHET, A.R. Sobrevivência e competitividade de estirpes de Rhizobium japonicum em cultivares de soja em um solo de Cerrado. In: SEMINÁRIO NACIONAL DE PESQUISA DE SOJA, 2., 1981, Londrina. Anais... Londrina: Embrapa-CNPSo, 1982. p.766- 777.

RAMOS, M.J.G; MAGALHÃES, N.F.M.; BODDEY, R.M. Native and inoculated rhizobia isolated from field grown Phaseolus vulgaris: effects of liming an acid soil on antibiotic resistance. Soil Biology and Biochemistry, Oxford, v.18, p.179-185, 1987.

SCOTTI, M.R.M.M.L. Efeito da adaptação aos solos de cerrado de estirpes de Bradyrhizobium japonicum nas suas diferentes estruturas e caracteres celulares. Rio de Janeiro: UFRRJ, 1993. 155p. Tese de Doutorado.

SCOTTI, M.R.M.M.L.; SÁ, N.M.H.; VARGAS, M.A.T.; DÖBEREINER, J. Avaliação da resistência a tetracidina, kanamicina, cloranfenicol de estirpes de Bradyrhizobium japonicum e Bradyrhizobium de Stylosanthes isoladas de solo de cerrados. Revista de Microbiologia, São Paulo, v.19, n.1, p.60-66, 1988 .

SCOTTI, M.R.M.M.L.; SÁ, N.M.H.; VARGAS, M.A.T.; DÖBEREINER, J. Streptomycin resistance of Rhizobium isolates from Brazilian cerrados. Anais da Academia Brasileira de Ciências, Rio de Janeiro, v.54, p.733-738, 1982

SKRDLETA, V.; KARIMOVA, J. Competition between two somatic serotypes of Rhizobium japonicum used as double-strain inocula in varying proportions. Archives of Microbiology, New York, v.66, p.25$-28,1969$.

SOMASEGARAN, P.; HOBEN, H.J. Methods in Legume - Rhizobium technology. Maui: University of Hawaii NifTAL, 1985. 367p.

TRIPLETT, E.W.; SADOWSKY, M.J. Genetics of competition for nodulation of legumes. Annual Review of Microbiology, Palo Alto, v.46, p.399$-428,1992$

VARGAS, A.A.T.; DENARDIN, N.D.; VAN BERKUM, P. Tolerância de rizóbios nativos do feijoeiro a antibióticos e sua relação com fatores de acidez do solo. Revista Brasileira de Ciência do Solo, Campinas, v.16, p.331-336, 1992a.

VARGAS, M.A.T.; MENDES, I. de C.; SUHET, A.R.; PERES, J.R.R. Fixação biológica de nitrogênio. In: ARANTES, N.E.; SOUZA, P.I.M. (Eds.). A Cultura da soja nos cerrados. Piracicaba: POTAFOS, 1993. p.159-182.

VARGAS, M.A.T.; SUHET, A.R.; MENDES, I. de C.; PERES, J.R.R. Duas novas estirpes de rizóbio para a inoculação da soja. Planaltina: Embrapa-CPAC, 1992b. 3p. (Embrapa-CPAC. Comunicado técnico, 62). 
VARGAS, M.A.T.; PERES, J.R.R.; SUHET, A.R. Fixação do nitrogênio atmosférico pela soja em solos de Cerrados. Informe Agropecuário, Belo Horizonte, v.94, p.20-23, 1982a.

VARGAS, M.A.T.; PERES, J.R.R.; SUHET, A.R. Reinoculação da soja em função dos serogrupos de Rhizobium japonicum predominantes em solos de cerrados. In: SEMINÁRIO NACIONAL DE PESQUISA DE SOJA, 2., 1981, Brasília. Anais... Londrina: Embrapa-CNPSo, 1982b. v.2, p.715-722.

VARGAS, M.A.T.; SUHET, A.R. Efeito de tipos e níveis de inoculantes na soja cultivada em um solo de cerrados. Pesquisa Agropecuária Brasileira, Brasília, v.15, n.3, p.343-347, 1980.

VARGAS, M.A.T.; SUHET, A.R.; MENDES, I. de C.; PERES, J.R.R. Soja. In: VARGAS, M.A.T.; SUHET, A.R.; MENDES, I. de C.; PERES, J.R.R. (Eds.). Fixação biológica de nitrogênio em solos de cerrados. Brasília: Embrapa-CPAC/SPI, 1994. p.15-38.
VINCENT, J.M. A manual for the practical study of root nodules bacteria. Oxford: Blackwell Scientific, 1970. 164p. (IBP Handbook, 15).

VINCENT, J.M. Factors controlling the legume-Rhizobium symbiosis. In: NEWTON, W.E.; ORME-JOHNSON, W.H. (Eds.). Nitrogen fixation. Baltimore: University Park Press, 1980. v.2, p.103-129 .

WAKSMAN, S.A. The actinomycetes: classification, identification and descriptions of genera and species. Baltimore: The Williams \& Wilkins, 1961. 236p.

WELLINGTON, E.M.H.; WILLIAMS, S.T. Preservation of actinomycete inoculum in frozen glycerol. Microbios Letters, Cambridge, v.6, p. 151-157, 1978.

WILLIAMS, S.T. Are antibiotics produced in soil? Pedobiologia, Jena, v.23, p.427-435, 1982.

WILLIAMS, S.T.; VICKERS, J.C. The ecology of antibiotic production. Microbiology Ecology, New York, v.12, p.43-52, 1986. 